\title{
Responsabilización institucional y comunicación en la Unión Europea*
}

\author{
Dra. Susana del Río Villar \\ Miembro del Comité de Expertos Independientes** de la Comisión Europea \\ Investigadora y Coordinadora Académica del Área Europa \\ en el Instituto de Gobernanza Democrática \\ Dra. María Luisa Sánchez Barrueco \\ Profesora Contratada Doctora de Derecho de la Unión Europea \\ Facultad de Derecho (Universidad de Deusto)
}

\begin{abstract}
Sumario: I. Introducción. - II. Responsabilización institucional y legitimidad europea. 1. Más allá del Estado de Derecho. 2. Aproximación al mapa de la responsabilización en la Unión Europea. 2.1. Multiplicidad de mecanismos responsabilizadores. 2.2. Sujetos y agentes, responsabilización «en nube». 2.3. Parámetros de responsabilización y su eficacia relativa. 3. Grietas en la responsabilización y legitimidad democrática. 3.1. La supervisión por un agente desentendido: los parlamentos nacionales. 3.2. La desviación de responsabilidad en la gestión presupuestaria descentralizada. - III. Comunicar Europa a los ciudadanos, recurso legitimador europeo de primer orden. 1. Un nuevo paradigma democrático: comunicación europea con visión de ida y vuelta. 2. Participación en la UE, comunicación y nueva gobernanza. 3. Un hito participativo para un modelo constituyente: la Convención europea. 4. Creatividad comunicativa para proyectos impulsores de ciudadanía europea. 5. Activadores de proyecto europeo: fortalecer la integración de la UE. 6. Esferas, conexión y comunicación: reflexiones sobre democracia europea y ciudadanos «integradores».-IV. Conclusión.
\end{abstract}

Resumen: Existen dos elementos que contribuyen a mejorar la calidad de la democracia en la Unión Europea aumentando la legitimidad del proceso de integración a los ojos de los ciudadanos. Por una parte, la responsabilización institucional constituye un vector de legitimación del proyecto europeo en la medida en que se introduce una responsabilización «en nube» donde todos los gestores públicos son a su vez controladores y controlados. Por otra parte, los métodos de comunicar Eu-

* Recibido el 9 de enero de 2012, aceptado el 6 de febrero de 2012.

** Miembro del Comité de Expertos independientes de la Comisión Europea en Science, Society and Governance y en Citizens and governance in the knowledge based society, task: «Democracy in a supranational context». 
ropa a los ciudadanos constituyen un recurso legitimador primordial porque al fortalecer la credibilidad del «sistema que funciona», aumenta el sentimiento de pertenencia europea ciudadana.

Palabras clave: control, legitimidad, gobernanza, ciudadanos, participación, comunicación europea.

Abstract: Two oft-forgotten elements contribute however to improving the quality of democracy in the European Union, increasing in turn the legitimacy of the integration process before the citizens. On the one hand, accountability represents a legitimacy factor for the European project as long as there is a «cloud accountability» in which every actor becomes both controller and controlled. On the other hand, proper ways to communicate Europe to the citizen become a primary legitimacy resource, for they heighten credibility on a functioning system and broaden in turn the sense of European belonging.

Keywords: accountability, legitimacy, democracy, governance, citizens, participation, European communication.

\section{Introducción}

La Unión Europea (UE) se halla inserta en una búsqueda perenne de legitimidad desde los orígenes del proceso de integración europea, que se ha intensificado desde finales del siglo Xx por los sucesivos y dolorosos rechazos populares en referéndum a distintos proyectos de reforma de los Tratados constitutivos. Debido a su condición de organización supranacional, se le exige constantemente que justifique su necesidad, utilidad, e integridad, sin lograr nunca desprenderse de su manto de vulnerabilidad al desapego de los ciudadanos europeos, contrariamente a lo que sucede con los Estados. No consuela saber que otras organizaciones internacionales también atraviesan crisis de legitimidad similares en los tiempos actuales.

En el ámbito europeo, la necesidad de integrar a los ciudadanos en el proyecto de integración ha impulsado la búsqueda de soluciones que aúnan consistencia, modernidad e imaginación en muy diversos ámbitos, algunos de los cuales se han reunido en este número monográfico. De modo complementario, el presente artículo propone una mirada sobre dos elementos que aumentan la legitimidad del proceso de integración a los ojos de los ciudadanos. Aunque resulta complicado medir el grado de influencia legitimadora que pueden conseguir en positivo, el potencial impacto negativo sobre la legitimidad de la Unión que tiene no dedicarles la atención necesaria no puede cuestionarse.

Inicialmente (II.), María Luisa Sánchez Barrueco propone una aproximación teórica a la responsabilización institucional como vector legitima- 
dor del proyecto europeo, explicando que en la UE se ha generado paulatinamente un sistema de responsabilización basado en la combinación de múltiples controles intensos y difusos «en nube» llamados a convertir a cada actor público a la vez en controlador y controlado.

A continuación (III.), Susana del Río Villar analiza en detalle tanto el proceso de participación en la UE como el modelo europeo para comunicar Europa a los ciudadanos. El análisis parte de la convicción de que la comunicación institucional de la idea de Europa, de cómo funciona y de lo que hace la Unión Europea, constituye un recurso legitimador de primer orden, pues al fortalecer la credibilidad del sistema se aumenta proporcionalmente el sentimiento de pertenencia europea ciudadana.

Pese a sus dinámicas esencialmente distintas, la responsabilización y la comunicación presentan una nota común: su eficacia como recursos legitimadores de la democracia europea depende estrechamente de que las instituciones europeas los apliquen mediante un ejercicio voluntario, consciente, incansable y adaptable a constantes mejoras.

\section{Responsabilización institucional y legitimidad europea}

La tentación de vaciar la noción de responsabilidad de todo contenido efectivo es peligrosa [pues] constituye la manifestación definitiva de la democracia.

\section{Comité de Expertos Independientes, $1999^{1}$}

La responsabilización se ha ido abriendo paso paulatinamente en la doctrina en español como traducción del inglés accountability, porque presenta la ventaja de sintetizar en un solo término múltiples conceptos como control democrático, rendición de cuentas, fiscalización, responsabilidad o transparencia, aunque es preciso confesar que la Real Academia de la Lengua no lo acepta todavía. Sin embargo, a los efectos del presente estudio, la responsabilización presenta la ventaja de reunir un conjunto interdisciplinar de fenómenos relacionados con la rendición de cuentas exigible a las autoridades públicas en un sistema democrático desde numerosas perspectivas. La multiplicidad de factores englobados dentro de este fenómeno complica enormemente la delimitación uniforme del concepto por parte de los autores que lo han abordado. Sin embargo, existe una coincidencia en que la ar-

1 COMITÉ DE EXPERTOS INDEPENDIENTES (PARLAMENTO EUROPEO), Primer informe sobre los presuntos casos de fraude, mala gestión y nepotismo en la Comisión Europea, 15 de marzo de 1999, http://www.europarl.europa.eu/experts/1_es.htm, apdo. 9.4.25 (última consulta de todas las referencias internet 31/01/2012). 
ticulación de mecanismos de responsabilización complementa y supera a la trilogía tradicional de soberanía, separación de poderes y Estado de derecho a la hora de determinar la legitimidad de un sistema político².

\section{Más allá del Estado de Derecho}

La responsabilización institucional implica la sujeción de las autoridades públicas a la obligación de rendir cuentas, en todas sus vertientes, a los ciudadanos. Esta concepción implica cuestionar que el poder sea democrático solamente por que su origen es legítimo, e implica exigir también que se ejerza legítimamente y los agentes públicos estén sujetos al escrutinio permanente de los demás, y expuestos a su sanción. No nos referimos exclusivamente a los condicionantes legales del ejercicio del poder y la sanción jurisdiccional. El estudio de la responsabilización engloba y supera los análisis centrados exclusivamente en las formas de control político o jurídico ${ }^{3}$. Desbordando los márgenes de la sujeción al imperio del Derecho, la responsabilización abarca igualmente otras figuras de contornos más imprecisos pero de virtualidad potencialmente equivalente respecto al objetivo de generar una cultura de la responsabilización en los órganos que gestionan lo público: responsabilidad ética, política o financiera.

Bovens definió accountability como la relación entre un actor y un foro, en la que el actor tiene la obligación de explicar y justificar su conducta, el foro puede plantear preguntas y emitir un juicio, y el actor puede enfrentarse a consecuencias ${ }^{4}$. La naturaleza de tal relación podía ser jurídica, política, sociológica o incluso simplemente moral. Pero además, entendemos que esta definición se centraba en el aspecto de control a pos-

${ }^{2}$ HARLOW, C., Accountability in the European Union, OUP, Nueva York, 2002, p. 7.

3 GRANT, R. y KEOHANE, R.O., "Accountability and abuses of power in world politics», American Political Science Review, vol. 99, n. ${ }^{\circ}$ 1, 2004, p.42; avisaron de que "deberíamos resistir la tentación de limitar el tema de la responsabilización al control democrático». A destacar igualmente las propuestas de MAGNETTE, P., LEQUESNE, CH., COSTA, O. y JABKO, N., «Conclusions», Journal of European Public Policy sobre accountability, vol. 10, n. ${ }^{\circ}$ 5, 2003; VAN GERBEN, W., «Political, ethical and financial and legal responsibility of the EU Commissionners», audiencia pública sobre Gobernanza en la Comisión ante el Comité de Control Presupuestario del Parlamento Europeo, 3-4 de octubre de 2007 http:// www.europarl.europa.eu/meetdocs/2004_2009/documents/dv/van_gerven_fin/van_gerven_ final.pdf

${ }^{4}$ BOVENS, M., «Analysing and assessing public accountability. A conceptual framework», European Governance Papers (EUROGOV), C-06-01, 2006, p. 9, http://www.connexnetwork.org/eurogov/pdf/egp-connex-C-06-01.pdf 
teriori, obviando ciertos elementos que refuerzan la responsabilización ex ante de los sujetos de responsabilización y así previenen y evitan comportamientos desviados. Se necesita por tanto el complemento de situación en la que acceda a la res publica un sujeto informado sobre el alcance de sus funciones y los límites de las mismas, un sujeto que sea sensible a las consecuencias del control sobre su actividad, todo ello dentro de un contexto generalizado de cultura de servicio al ciudadano.

En el ámbito de la Unión Europea (UE), tanto documentos oficiales como doctrina resaltan habitualmente la importante contribución de la responsabilización a la legitimidad democrática de la organización ${ }^{5}$. La UE actual abunda en técnicas e instrumentos cuyo objetivo es mejorar la calidad de la gobernanza democrática mediante una responsabilización institucional meta-jurídica donde iniciativas legislativas orientadas a mejorar la transparencia, la rendición de cuentas o la supervisión extrajudicial por parte de órganos consultivos de distinta naturaleza coexisten con aspectos organizativos quizás menos llamativos como el establecimiento de una adecuada política de comunicación institucional, la selección y formación del personal o la integración transversal de los valores propios de la organización en los procedimientos de adopción, ejecución y supervisión de las decisiones.

\section{Aproximación al mapa de la responsabilización en la Unión Europea}

Durante mucho tiempo la legitimidad de la UE residió en su capacidad de solucionar los problemas de los ciudadanos (gobierno para el pueblo, o output legitimacy), en las últimas décadas se han incorporado mecanismos de democracia participativa que permiten aumentar el sentimiento de pertenencia ciudadana (gobierno del pueblo o input legitimacy) y ahora en cambio, se alzan voces a favor de prestar atención a los procesos de rendición de cuentas como coadyuvantes a la legitimación del sis-

5 COMISIÓN EUROPEA, La Gobernanza europea, un libro blanco, COM (2001) 428 de 25 de julio de 2001. En concreto, la Comisión apelaba a la asunción de «responsabilidad» por parte de las instituciones de la UE, pero de manera complementaria exigía «una mayor responsabilización de los Estados miembros y de todos los agentes que participan en el desarrollo y aplicación de las políticas de la UE en los distintos niveles», p. 11. Entre la doctrina, destacaremos ARNULL, A. y WINCOTT, D. (eds.), Accountability and legitimacy in the European Union, Oxford, OUP, 2002; BOGDANOR, V., Legitimacy, accountability and democracy in the European Union, A Federal Trust Report, 2007, http://www.fedtrust.co.uk/ admin/uploads/FedT_LAD.pdf; BOVENS, M., CURTIN, D., 'T HART, P. (eds.), The real world of EU accountability, What deficit?, Oxford, OUP, 2010. 
tema político ${ }^{6}$ (throughput legitimacy ${ }^{7}$ ). En este sentido, se observa una profunda evolución desde los años noventa en la UE, caracterizada por el aumento de los mecanismos de control sobre cualquier organismo dotado de alguna forma de autoridad pública, hasta el punto de desafiar la concepción clásica de democracia fundamentada en el control del gobierno por el parlamento. Coexisten dinámicas variadas de responsabilización en la Unión Europea, entre instituciones, de las instituciones sobre los Estados miembros, en ámbitos diferentes, con consecuencias diferentes. Esta complejidad dificulta la obtención de un concepto integral de la responsabilización, a riesgo de caer en una reducción simplista carente de utilidad práctica. En cambio, resulta deseable profundizar en los distintos elementos integrantes de la responsabilización, atendiendo especialmente a su eficacia. Las reflexiones siguientes pretenden así contribuir a una taxonomía de mecanismos responsabilizadores que permita a estudios posteriores evaluar el grado de responsabilización institucional en la Unión. Se abordarán sucesivamente la naturaleza, sujetos y eficacia de los mecanismos de responsabilización.

\subsection{MulTIPLICIDAD DE MECANISMOS RESPONSABILIZADORES}

La naturaleza de la responsabilización es múltiple. En el pasado se acentuaba la responsabilidad política o jurídica conforme a procedimientos consagrados en el ordenamiento jurídico, pero el momento presente está caracterizado por una exigencia de responsabilidad, intensa y constante pese a sus contornos difusos.

Ya en 1999 el Comité de Expertos Independientes (CEI) del PE declaró que el comportamiento de la Comisión debe sujetarse no sólo a la responsabilización política colectiva de la Comisión ante el Parlamento Europeo (PE) y la responsabilización disciplinaria individual de los comisarios ante el Tribunal de Justicia, sino también a la «responsabilidad ética», entendida como la necesidad de cumplir los niveles más elevados exigibles a una Administración Pública, por su efecto sobre la imagen de la UE ante el público

${ }^{6}$ En especial, CURTIN, D. y WILLE, A. (eds.) Meaning and practice of accountability in the EU multilevel context. Mannheim, CONNEX, 2008; FISHER, E., «The European Union in the age of accountability», Oxford Journal of Legal Studies, 2004, vol. 24 n. ${ }^{\circ} 3$, pp. 495-515.

${ }^{7}$ Los términos input, output y throughput legitimacy se atribuyen a SCHARPF, F.W., Governing in Europe, Oxford, OUP, 1999; pero escasos autores analizan la calidad de la gobernanza relativa a la transparencia o rendición de cuentas, SCHMIDT, V., «Democracy and legitimacy in the EU revisited: Input, output and throughput», KFG Working Paper Series n. $^{\circ} 21$, noviembre de 2010, http://userpage.fu-berlin.de/kfgeu/workingpapers/Working PaperKFG_21.pdf, p. 8 . 
general. Sus reflexiones se restringían a la Comisión por el mandato asignado al CEI pero son extrapolables al conjunto de instituciones europeas.

Entendía el CEI que la dificultad de perfilar con exactitud el comportamiento correcto no impide reconocer «un núcleo común de "normas mínimas"» más allá de las explicitadas en la ley. Partiendo de la exégesis de las disposiciones del Tratado sobre los deberes de los comisarios (hoy arts. 17.5 TUE y 245 TFUE), el CEI declaró que solo el respeto a las normas de independencia, integridad, discreción, responsabilidad y transparencia permitiría a los comisarios gozar de la autoridad y credibilidad imprescindibles para ejercer el liderazgo que se les exige ${ }^{8}$.

El afán sistematizador de los mecanismos de responsabilización nos impulsa a clasificar los mecanismos de responsabilización en función de su naturaleza jurídica, política o financiera pues cada una de ellas presenta dinámicas específicas.

La responsabilización jurídica se relaciona directamente con el imperio del Derecho, en su más amplio sentido, durante la definición y gestión de las políticas públicas. Abarcaría consideraciones muy diversas relativas al respeto de los procedimientos de decisión (bases jurídicas, consultas previas, mayorías necesarias, publicidad, etc.) o a los derechos fundamentales en la gestión pública (respeto de los principios de contradicción en los procedimientos sancionadores, adecuada motivación, principio de confianza legítima, etc.), compartiendo todas ellas la característica de hallarse insertas en una norma jurídica y, por tanto, un grado elevado de certidumbre.

El enfoque político, por su parte, aplica criterios de oportunidad y eficiencia política, que presentan una aplicación más subjetiva. Exige al gestor público explicaciones sobre los intereses subyacentes a las opciones de política pública, la aptitud de las medidas para alcanzar los objetivos, y la adecuación de la organización administrativa de una política concreta. También atiende a la representación del público general cuando propugna la simplificación de la legislación.

Finalmente, la responsabilización financiera interroga a los gestores sobre el uso de los fondos públicos conforme a los criterios de legalidad, regularidad y buena gestión financiera. En el marco de la UE, el criterio de legalidad controla que la operación sea compatible con el presupuesto como norma legal; el criterio de regularidad atiende al respeto de las reglas procedimentales de gestión recogidas en el Reglamento Financiero u otras normas sectoriales (p.ej., reglamentos de los fondos estructurales). El criterio de buena gestión financiera atiende a que el gasto sea lo menos costoso posible y alcance sus objetivos optimizando los resultados.

${ }^{8}$ CEI, Primer informe..., op. cit., apdos. 1.4-1.6. 


\subsection{SUJETOS Y AGENTES, RESPONSABILIZACIÓN «EN NUBE»}

La exigencia de un «ejercicio permanente» de responsabilización constituye otra aportación fundamental del CEI, admitiendo que los controles existentes en la Comisión hasta 1999 no solo no evitaron, sino que propiciaron la dilución de responsabilidades en la jerarquía, de modo que era «difícil encontrar a alguien [con] el más mínimo sentimiento de ser responsable». De ahí la conclusión esencial: «[c]ada uno debe sentirse responsable de lo que gestiona» ${ }^{9}$.

El desplazamiento del foco de atención desde la tradicional existencia de controles hacia la ética individual y el autocontrol del gestor público configura una responsabilización institucional «en nube» ante el observador externo. Cada actor institucional se convierte alternativamente en sujeto pasivo o agente de responsabilización, más allá de las relaciones clásicas basadas en la responsabilización del poder ejecutivo ante el legislativo (política) o judicial (jurídica). La Comisión constituye el sujeto pasivo del control por excelencia en el marco de la gestión de políticas: los Estados Miembros (EM) controlan que atienda debidamente a sus intereses en la definición y ejecución de las políticas mediante la comitología, el PE y el Consejo efectúan un control político sobre su gestión; el Tribunal de Cuentas Europeo (TCE) mantiene una supervisión crítica sobre la forma como emplea el presupuesto comunitario a través de sus informes anuales y especiales; pero la Comisión se convierte a su vez en agente de responsabilización cuando rehúsa reembolsar el gasto agrícola o estructural indebidamente realizado a nivel nacional o cuando persigue los incumplimientos estatales del ordenamiento jurídico de la Unión (art. 268 TFUE). Cabe aplicar idéntico razonamiento al resto de instituciones y organismos europeos.

Existen agentes internos y externos de responsabilización, aunque solo desarrollaremos los primeros ${ }^{10}$. Por agentes internos de responsabilización entendemos los órganos que se hallan incardinados dentro del entramado institucional de la Unión, incluidos los niveles supranacional y estatal, ante los que deben responder los demás órganos u instituciones europeos. Su mera existencia ya constituye un factor de legitimación de cara a la ciuda-

9 Ibid., apdo. 9.4.25.

${ }^{10}$ Otros agentes externos (no están integrados en el entramado institucional de la UE en sus distintos niveles) producen un indudable impacto en la responsabilización de las instituciones europeas. Algunos ejemplos de agentes externos relevantes serían otras organizaciones intergubernamentales (p.ej. Consejo de Europa, OIT, ONU), o no gubernamentales cuyo escrutinio sobre la llevanza de políticas europeas puede minar la credibilidad del sistema a los ojos del público y generar reacciones en el seno del sistema (p.ej. Amnesty International, o Transparency International), think tanks, o medios de comunicación. Excluidos todos ellos de esta parte por motivos de espacio, vid. infra III sobre su papel en la comunicación institucional. 
danía. Los agentes responsabilizadores europeos más potentes son el Parlamento Europeo (PE) y el Tribunal de Justicia (TJUE): ambos tienen la capacidad de exigir responsabilidades desde la perspectiva política o jurídica, respectivamente, en cualquier ámbito de competencia de la Unión, siendo así que las consecuencias potenciales de la rendición de cuentas contemplan hasta la dimisión del sujeto pasivo del control, por obligación jurídica o presión política equivalente, o un desvalor jurídico que puede llevar aparejado una sanción pecuniaria institucional y hasta personal ${ }^{11}$. Junto al PE y al TJUE, existe una pluralidad de organismos consultivos que supervisan la actividad de los demás, pero limitados a un enfoque específico, o en un ámbito material específico: pueden ser instituciones europeas como el Tribunal de Cuentas, que persigue garantizar al ciudadano que los fondos europeos se emplean correctamente ${ }^{12} \mathrm{o}$ el Banco Central en el ámbito monetario ${ }^{13}$; órganos como el Comité de las Regiones o el Comité Económico y Social; organismos unipersonales como el Defensor del Pueblo o el Supervisor Europeo de Protección de Datos. También las operaciones de la política de defensa, que suscitan reparos por el alcance de su inmunidad en materia de derechos humanos, incorporan ahora órganos de supervisión ad hoc para aumentar su responsabilización ${ }^{14}$. Finalmente, no debe olvidarse la supervisión ejercida indirectamente sobre los EM mediante las agencias euro-

${ }^{11}$ P.ej. la violación de la obligación de secreto profesional respecto a las empresas entraña obligación de resarcir los daños materiales sufridos (Asunto T-88/09, Idromacchine contra Comisión, Sentencia del Tribunal General de 8 de noviembre de 2011, DO C370 de 17 de diciembre) pero la condena en responsabilidad civil (art. 340 TFUE) puede ser repercutida al funcionario responsable en caso de falta personal grave (art. 22 del Estatuto de los Funcionarios, Reglamento 31 (CEE), DO L45 de 14 de junio de 1962, p. 1385, actualizado a 14 de julio de 2009); creemos empero que la ausencia de jurisprudencia indica que no se ha aplicado esta disposición.

12 El Tribunal de Cuentas controla la buena gestión financiera del presupuesto de la Unión (art. 287.2 TFUE) y curiosamente, aunque el ordenamiento jurídico lo configure como una institución de asistencia técnica a las funciones del Parlamento Europeo y el Consejo en materia de control presupuestario, el Tribunal ha actuado siempre como si sus auténticos «clientes» fueran los ciudadanos europeos, y no otras instituciones de la Unión. SÁNCHEZ, M.L., El Tribunal de Cuentas Europeo. La superación de sus limitaciones mediante la colaboración institucional, Madrid, Dykinson, 2008, pp. 131 y ss.

${ }^{13}$ Protocolo n. ${ }^{\circ} 4$ anexo al Tratado, sobre los estatutos del Sistema Europeo de Bancos Centrales y del Banco Central Europeo.

14 Desde 2005 todas las operaciones incorporan un asesor de derechos humanos (vid. SÁNCHEZ, M.L., «The promotion and protection of Human Rights during European Security and Defence Policy operations: in-between a spreading state of mind and an unsolved concern», en WETZEL, J. (ed.), The European Union as a global player in the field of $\mathrm{Hu}$ man Rights, Routledge, Londres, 2012, pp. 157-173). Adicionalmente, para EULEX-Kosovo se ha creado un comité de revisión de alegaciones en materia de derechos humanos (Human Rights Review Panel). 
peas ${ }^{15}$. La proliferación de mecanismos variados de exigencia de responsabilidades, superpuestos, conforman una «nube» de responsabilización. En ella, cada agente responsabilizador está llamado frecuentemente a su vez a responder ante otros agentes, como consecuencia de lo cual se genera un contexto general de rendición de cuentas que desemboca en una cultura de responsabilidad. Resulta difícil determinar en qué medida la existencia de mecanismos responsabilizadores eficaces contribuye a la legitimación del sistema en su conjunto, pero es evidente que su ausencia tiene un efecto deslegitimador cuando el ciudadano toma conocimiento de ello.

\subsection{PARÁMETROS DE RESPONSABILIZACIÓN Y SU EFICACIA RELATIVA}

Todo mecanismo responsabilizador encaja en uno de los tres niveles siguientes de intensidad. El primer nivel, más laxo, contribuye a generar un contexto de responsabilización de la gestión de políticas públicas, respecto a las dimensiones antes mencionadas. El agente responsabilizador solo verificaría el cumplimiento formal de los procedimientos establecidos. Encajarían aquí, por una parte, diversos aspectos que vienen siendo objeto de modernización en las administraciones públicas de nuestro entorno sobre: selección de personal ${ }^{16}$, códigos deontológicos de conducta ${ }^{17}$, racionaliza-

15 El control de los EM no forma parte del mandato expreso de ninguna agencia europea pero dimana de sus actividades, cuando en su ámbito competencial citan críticamente a determinados EM. Vid. el informe de 21 de noviembre de 2011 «Fundamental rights of migrants in an irregular situation in the EU» de la FRA (Agencia europea de derechos fundamentales), bajo una apariencia comparativa-descriptiva, contiene críticas a los EM menos garantistas, http://fra.europa.eu/fraWebsite/attachments/FRA_2011_Migrants_in_an_irregular_ situation_EN.pdf. En esta línea, los organismos de supervisión financiera creados en enero de 2011, Autoridad Bancaria Europea, Autoridad Europea de Seguros y Pensiones de Jubilación y Autoridad Europea de Valores y Mercados, creadas respectivamente por Reglamentos (CE) n. ${ }^{\circ} 1093 / 2010,1094 / 2010$ y 1095/2010 del PE y el Consejo, de 24 de noviembre de 2010, DO L331 de 15 de diciembre.

${ }^{16}$ La selección de personal con formación previa en materia de derechos humanos es un eje de la estrategia preventiva de violaciones durante las operaciones europeas de defensa. CONSEJO, «Civilian capabilities improvement Conference 2006. Ministerial Declaration», Bruselas, 13 de noviembre de 2006, http://www.consilium.europa.eu/uedocs/cmsUpload/ civilian_crisis_management_20.11.pdf

17 Además del Código de conducta para los funcionarios hay uno más estricto para los comisarios (http://ec.europa.eu/commission_2010-2014/pdf/code_conduct_en.pdf), endurecido en abril de 2011 con limitaciones más estrictas del secreto profesional tras el cese en el cargo, para evitar la práctica de revolving door, COMISIÓN, Comunicado de prensa, 20 de abril de 2011, IP 11/498. El código de conducta de los europarlamentarios también se ha endurecido recientemente, PARLAMENTO EUROPEO, Decisión de 1 de diciembre de 2011, sobre las modificaciones del Reglamento relativas a un Código de conducta de los diputados al PE en materia de intereses económicos y conflictos de intereses, P7_TA-PROV(2011)0540. 
ción y definición precisa de los puestos de trabajo, reglas de publicidad, transparencia y acceso a los documentos públicos ${ }^{18}$, correcta definición de los objetivos de los programas europeos, o la obligación del sujeto pasivo de informar periódicamente sobre su actividad ${ }^{19}$.

En un nivel intermedio de exigencia se hallarían los mecanismos que obligan al sujeto pasivo a responder ante un agente externo, situación incómoda por la obligación de justificarse, a la que subyace cierta desconfianza sobre la rectitud de su actividad, pero la responsabilización no amenaza la supervivencia del sujeto en este punto, al menos no directa y automáticamente. Encajarían en este apartado, entre otros, las preguntas orales y escritas en el PE, las audiencias públicas, las explicaciones al Defensor del Pueblo, la mención en el informe de un órgano consultivo (TCE, CES, CR), el Comité ad hoc de Ética en la Comisión o el Comité consultivo sobre la Conducta de los Diputados en el PE.

El nivel más exigente de responsabilización estaría integrado por los procedimientos sancionadores. La sanción puede revestir una naturaleza disciplinaria (pérdida de privilegios, suspensión de funciones y/o sueldo $^{20}$ ), jurídica (exigencia de responsabilidad ante los tribunales en la vía administrativa o penal) o política, en cuyo caso, puede llevar aparejada bien la remoción del cargo, o bien la colocación del sujeto en una posición tan difícil que se le obliga en la práctica a dimitir. La existencia de un mecanismo sancionador solo contribuye a la responsabilización en la medida en que el sujeto realice un análisis de los costos transaccionales entre el beneficio reportado por el comportamiento desviado y la potencial evasión de la sanción en el futuro, y concluya que no le compensa, por ello conviene evaluar las lagunas de responsabilización surgidas durante la aplicación del mecanismo sancionador. Este análisis reviste una gran complejidad por la dificultad de acceso a la información y el grado de discrecionalidad que disfrutan las instituciones implicadas: p.ej., índice de incumplimientos de Estado que la Comisión no considera conveniente

18 El Registro de Transparencia Común, revisado en junio de 2011, obliga a toda entidad que pretenda influir en la gestión pública de la UE (grupos de interés, ONG, think tanks, despachos de abogados, etc.) a registrarse y a cumplir un código de conducta, con denuncias y sanciones en caso de incumplimiento. COMISIÓN, Comunicado de prensa, 23 de junio de 2011, IP 11/773.

19 Por ejemplo, la Comisión presentó 165 informes de evaluación al Consejo y al Parlamento sobre distintos instrumentos jurídicos, políticos o financieros en 2011.

20 El nuevo art. 153 del Reglamento interno del PE prevé: remoción del cargo de ponente, pérdida de dietas por valor de 2 a 10 días, suspensión temporal de las actividades parlamentarias (salvo el derecho a voto) hasta 10 días, y publicidad de las sanciones impuestas en el sitio web oficial. 
llevar al TJUE ${ }^{21}$, índice de ejecución nacional tardía o defectuosa de las sentencias de incumplimiento dictadas por el TJUE, índice de multas impuestas a los Estados por esta causa, índice de divergencia en la aplicación del derecho de la Unión por falta de presentación de cuestiones prejudiciales por jueces nacionales, y un largo etc.

Sea cual sea el nivel de intensidad aplicado, consideramos que, en un contexto de responsabilización institucional eficaz, existen mecanismos de responsabilización que, por separado o conjuntamente, disuaden los comportamientos desviados o persiguen los que se produzcan, de manera que se proscriba la impunidad y se prevengan comportamientos similares en el futuro.

Constituye un error frecuente prejuzgar la eficacia de los mecanismos de responsabilización en función de la materia en que se ejerce, entendiendo que los mecanismos jurídicos aumentan de modo más eficaz la responsabilización. Ello solo es cierto en la medida en que se trate de mecanismos completos en su configuración, cuando la propia norma delimita los diferentes elementos de responsabilización (obligación, sanción, sujeto pasivo y agente), de modo que se derive un castigo automático para el comportamiento desviado. Usualmente, por el contrario, la mera existencia de mecanismos jurídicos de control no produce automáticamente la responsabilización de sus destinatarios, bien porque el régimen sancionador es incompleto, bien porque los agentes encargados de ponerlo en práctica no lo aplican, voluntariamente o por incompetencia. Por el contrario, mecanismos de soft law aparentemente poco intensos pueden lograr un impacto responsabilizador sustancial combinados entre sí y con otros factores externos, como puede ser una situación de crisis económica o de legitimidad democrática. La diferencia fundamental entre ambos es la predictibilidad o aleatoriedad. Los mecanismos jurídicos, y en menor medida los mecanismos relativos al control financiero, fundamentan su eficacia en la percepción de que existe una sanción futura que amenaza realmente al sujeto pasivo, mientras que los mecanismos políticos, salvo excepciones, son generalmente percibidos como «blandos» porque se desconoce si existe sanción, si se producirá siquiera, y con qué alcance afectará a la supervivencia del sujeto.

Ilustraremos las consideraciones anteriores mediante un ejemplo comparativo entre dos mecanismos de control a cargo del Parlamento: la moción

${ }^{21}$ Dejando a salvo la no incorporación de directivas, que supone el envío automático de carta de emplazamiento, la Comisión aplica una discrecionalidad sobre la conveniencia de iniciar actuaciones contra el Estado incumplidor que motiva susceptibilidades acerca de su ecuanimidad. CRAIG, P. y DE BÚRCA, G., EU Law. Text, cases and materials, 5. a ed., Oxford, OUP, 2011, pp. 415-418. 
de censura y la intervención en los nombramientos de otras instituciones mediante el trámite de audiencia previa. La moción de censura constituye el mecanismo de responsabilización política de mayor intensidad, pues se halla regulada en el Tratado (art. 234 TFUE) y conduce a la dimisión colectiva del colegio de comisarios. Sin embargo, ninguna moción de censura ha prosperado en la práctica, bien por su restrictiva regulación, bien porque el PE prefiere utilizar tal poder de amenaza a la Comisión como palanca para conseguir cambios. En claro contraste, el PE ha desarrollado un trámite de audiencia previa al nombramiento en otras instituciones, al margen del Tra$\operatorname{tado}^{22}$, mediante el cual se invita a los candidatos a comparecer en audiencia pública ante la comisión pertinente para responder a las preguntas de los eurodiputados. En realidad, este trámite es todo menos inocente: el PE lo ha convertido por la vía de hecho en una investigación sobre la competencia, independencia e integridad de los candidatos. Viendo las retiradas espontáneas de candidaturas ocurridas hasta el momento, se deduce que la presión ejercida sobre los candidatos que desagradan al PE es sin duda efectiva ${ }^{23}$. Recordemos también que el acuerdo marco PE-Comisión de 20 de octubre de 2010 obliga al Presidente de la Comisión a «considerar seriamente» la retirada de confianza a un comisario, en el sentido del artículo 17.6 TUE, si el PE se lo pide ${ }^{24}$.

Completar el análisis individual de eficacia de los mecanismos responsabilizadores con una observación global sobre el sistema permite extraer dos conclusiones adicionales, una positiva y otra negativa. En sentido positivo, subrayar que la simple existencia de un mecanismo de responsabilización constituye un factor positivo de responsabilización con independencia de la eficacia real que despliegue el mecanismo en la relación agente-sujeto individual. Nunca se ha reclamado la supresión de un mecanismo de responsabilización debido a su ineficacia, como mucho, su mejora. Conforme a una visión sistémica, el mecanismo de responsabilización despliega una eficacia legitimadora en todo caso, constituyendo la única excepción el me-

${ }^{22}$ Tanto el art. 17.7 TUE sobre el nombramiento de los comisarios como el art. 286 TFUE sobre el nombramiento de los miembros del Tribunal de Cuentas lo ignoran, frente a los art. 105 a 109 del Reglamento interno del PE, 7 de noviembre de 2011, http://www.europarl. europa.eu/sides/getLastRules.do?language $=E S \&$ reference $=$ TOC, que contemplan la audiencia previa en la designación de la Comisión, TJUE, TCE y Comité ejecutivo del BCE

${ }^{23}$ Durante la formación del gabinete Barroso II, la candidata propuesta búlgara Rumiana Jeleva retiró espontáneamente su candidatura el 18 de enero de 2010, debido al balance negativo de su audiencia. No se hallaba sujeta a obligación jurídica alguna de retirarse, pero la presión de tomar posesión del cargo con la oposición del PE prevaleció. Idéntica fortuna tuvo el candidato chipriota a miembro del TCE en 2004.

24 Acuerdo marco sobre las relaciones entre el Parlamento Europeo y la Comisión Europea, de 20 de octubre de 2010, DO L304 de 20 de noviembre, apdo II.3. 
canismo que presenta tales lagunas de responsabilización que, a los ojos del público, constituye una mera operación de imagen o una maniobra de distracción, teniendo un resultado deslegitimador.

En sentido negativo, la perspectiva sistémica permite apreciar las lagunas producidas por desviación de responsabilización. En efecto, determinados sujetos persisten en su comportamiento desviado porque se benefician impunemente de una laguna de responsabilización, sabedores de que las consecuencias recaen en otro sujeto o eventualmente sobre el sistema como un todo. El caso más paradigmático es la asimetría existente entre la titularidad de la gestión del presupuesto comunitario y su ejercicio real: los fallos en la gestión del presupuesto comunitario por autoridades públicas de los Estados Miembros no conllevan la responsabilización de éstas en sede europea más que en casos extremadamente graves, en su lugar, se atribuye la responsabilidad a la Comisión. Retomamos este tema en la siguiente parte.

\section{Grietas en la responsabilización y legitimidad democrática}

Interpretamos el término "grieta» como punto del sistema en que se produce una evasión de responsabilización institucional cualesquiera sean los motivos. Sin embargo, la UE tiene que justificar permanentemente su legitimidad como sistema, frente al nivel estatal. De ahí que toda grieta de responsabilización origine un cuestionamiento popular del propio proceso de integración, y no de su «gobierno» o de los sujetos auténticamente responsables de tal fuga de responsabilización. Esta percepción se agrava especialmente por la complejidad de la estructura de gobernanza en la UE.

La insuficiente responsabilización puede traer causa de una configuración insuficiente del mecanismo para alcanzar su objetivo con eficacia, de un agente negligente en su labor de supervisión del sujeto pasivo, de que los diversos niveles de responsabilización no encajan bien entre sí en el marco de la gobernanza multinivel. Respecto al primero, consideramos que todos los mecanismos de responsabilización existentes en la UE actual son mejorables, ya sea en su configuración o en su eficacia, pero no más que aspectos análogos de las administraciones estatales, y lo importante es que los órganos decisorios permanezcan sensibles a las llamadas de atención efectuadas por otros agentes y procedan a realizar mejoras. Por eso, nos centraremos en las, en nuestra opinión, principales grietas de responsabilización institucional que padece el proceso de integración europea. Estas responden a zonas grises entre los respectivos círculos de gobernanza multinivel; además, inciden de modo asimétrico sobre la legitimidad de los mismos, de modo que la UE se convierte en el chivo expiatorio expuesto públicamente. 
Dos ejemplos ilustrarán brevemente esta reflexión: la escasa intervención de los parlamentos nacionales en la responsabilización de la Comisión y la gestión compartida del presupuesto europeo.

\subsection{LA SUPERVISIÓN POR UN AGENTE DESENTENDIDO: LOS PARLAMENTOS NACIONALES}

Actualmente, la responsabilización política europea se divide entre el PE y los parlamentos nacionales ${ }^{25}$. Estos contribuyen a reducir el déficit democrático de la UE supervisando al representante del EM en el Consejo y controlando el respeto a la subsidiariedad mediante el mecanismo de alerta temprana (MAT) sobre propuestas legislativas ${ }^{26}$. Sin embargo, la implicación de unos y otros parlamentos es desigual ${ }^{27}$ : unos se resignan a un control de baja intensidad, otros desarrollan estrategias proactivas de control. Mientras la comisión de asuntos europeos del parlamento danés dicta instrucciones de voto en el Consejo a los ministros, y los nueve comités y subcomités competentes en el parlamento británico supervisan férreamente las políticas de la UE mediante audiencias a actores clave y numerosos informes de posición públicos (42 en 2010-11), otros EM no cuentan con mecanismos de intensidad pareja. En España, la configuración legal de la comisión mixta Congreso-Senado para la UE responde tradicionalmente a una responsabilización política ex post del gobierno central de baja intensidad, sustanciada en la doble obligación a cargo del gobierno de informar a la comisión sobre las propuestas legislativas que afecten los intereses de España y sobre los resultados de los Consejos Europeos ${ }^{28}$. En 2011 la reforma de la Ley 8/9429 introdujo un sistema de audiencias previas a las reuniones del Consejo, obligatorias para los miembros del gobierno y facultativas para los miembros de gobiernos autonómicos (nuevos arts. 8 y 10).

La transferencia de competencias a la UE genera por tanto cierto grado de déficit democrático siempre, lo que no sucede en igual medida con la

25 RIDEAU, J., «El papel de los Parlamentos nacionales en la arquitectura europea», en GARCÍA DE ENTERRÍA, E. (dir.), La encrucijada constitucional de la Unión Europea, Civitas, Madrid, 2002, pp. 327-350, p. 335.

${ }^{26}$ Protocolo $n .{ }^{\circ} 2$ sobre la aplicación de los principios de subsidiariedad y proporcionalidad, anexo al TUE.

27 JANS, Th. y PIEDRAFITA, S., «The role of national parliaments in European decision-making», Eipascope, 2009, 1, p. 19.

${ }^{28}$ Las mociones que instan al gobierno a defender posiciones determinadas en el seno del Consejo son totalmente puntuales y en temas inconexos.

${ }_{29}$ Ley 8/94, de 19 de mayo de 1994, BOE n. ${ }^{\circ} 120$, de 20 de mayo, modificada por Leyes 24/2009, de 22 de diciembre de 2009 (BOE n. ${ }^{\circ} 308$, de 23 de septiembre), y 38/2010, de 20 de diciembre de 2010 (BOE n. ${ }^{\circ} 309$, de 21 de diciembre). 
responsabilización política: la diferencia estriba en el grado de responsabilidad que decida asumir cada parlamento nacional.

Esta conclusión se refuerza al analizar la aplicación del MAT post-Lisboa. Los parlamentos nacionales pueden objetar individualmente a la compatibilidad con el principio de subsidiariedad de proyectos de acto legislativo (art. 3 del Protocolo n. ${ }^{\circ}$ 2) en ámbitos compartidos, si entienden que la UE sobrepasa los límites de su competencia. Un primer análisis del MAT concluye que su configuración legal es insuficiente para aplicar una responsabilización política de grado intenso, no solo porque se aplica en la fase inicial del procedimiento y no versa sobre el documento final, sino sobre todo por su falta de valor jurídico vinculante: aunque nueve parlamentos nacionales se opusieran, el titular de la iniciativa legislativa solo estaría jurídicamente obligado a reexaminar el proyecto, y si lo motiva, puede mantenerlo. En el procedimiento ordinario, esta situación obliga a PE y Consejo a evaluar detenidamente el respeto de la subsidiariedad, pudiendo rechazar definitivamente la propuesta en primera lectura, pero no son los parlamentos nacionales quienes esgrimen la «tarjeta roja», no disponen de un derecho de veto sobre la propuesta de la Comisión.

El análisis político del MAT es más positivo, entendiendo que este control político tendrá un impacto sobre las instituciones europeas. La Comisión mostrará teóricamente flexibilidad para con los parlamentos nacionales y revisará sus propuestas ante un número significativo de dictámenes motivados. El problema es que la práctica actual dista mucho de tal situación: estadísticas del MAT en $2010^{30}$ muestran que una proporción alarmantemente alta de parlamentos no abordan temas de subsidiariedad o bien no se alcanza el umbral exigido (cinco es el máximo hasta ahora). La contribución española ha sido escasa. En 2010, el parlamento español no emitió dictamen sobre ninguna de las 42 propuestas analizadas ${ }^{31}$ y en 2011 se emitieron dos dictámenes motivados ${ }^{32}$.

En suma, el legislador de la Unión recondujo la posición de los parlamentos nacionales para mitigar el déficit democrático acumulado con las su-

${ }^{30}$ COMISIÓN, Report on subsidiarity and proportionality (18th Report on Better Lawmaking covering the year 2010), COM (2011) 344 final, 10 de junio de 2011.

31 El análisis del diario de sesiones de la comisión mixta no permite apreciar que las propuestas más discutidas en otros EM suscitaran debate de entidad, probablemente prevaleció la supervisión de la Presidencia española, pero cerró el paso a dictámenes motivados emitidos a nivel autonómico (nuevo art. 6 de la Ley 8/1994) pues estos solo se transmiten como adjunto al dictamen del parlamento español. CAMISÓN YAGÜE, J.A., «La Asamblea de Extremadura y el control del principio de subsidiariedad a través del mecanismo de alerta temprana», Revista d'Estudis Autonómicos i Federals, 2011, pp. 264-320.

32 Dictamen 1/2011 y 2/2011, BO de las Cortes Generales A n. ${ }^{\circ} 446$, de 22 de junio de 2011. 
cesivas reformas de los tratados constitutivos, mediante un mecanismo responsabilizador cuya eficacia jurídica pudiera ciertamente incrementarse; sin embargo, la grieta de responsabilización estriba hoy por hoy en la escasa asunción de responsabilidad por parte de un número elevado de parlamentos.

\subsection{LA DESVIACIÓN DE LA RESPONSABILIDAD EN LA GESTIÓN PRESUPUESTARIA DESCENTRALIZADA}

La gestión y control de los fondos europeos ofrece un ejemplo de gobernanza multinivel con grietas de responsabilización ${ }^{33}$ que generan un efecto deslegitimador asimétrico del sistema. Frente a la opinión generalizada de que es Bruselas quien gasta el presupuesto de la UE, es preciso recordar que la gestión centralizada por la Comisión es un método absolutamente marginal, siendo la gestión descentralizada por parte de autoridades nacionales la regla general que se aplica a las partidas presupuestarias más importantes (en 2010, los fondos agrícolas representaron el $47 \%$ y los fondos estructurales el $41 \%$ ).

Paradójicamente, el dinero se gasta a nivel de EM pero la Comisión es exclusivamente responsable por la gestión presupuestaria (art. 317 TFUE), cuando en realidad solo conserva labores de planificación general y de control financiero interno. El control financiero externo es efectuado por el Tribunal de Cuentas Europeo y el control político sobre la gestión corresponde al PE, por recomendación del Consejo, en el marco del procedimiento de descargo presupuestario (art. 319 TFUE). Lo sorprendente es que ambos controles apuntan siempre hacia la Comisión, no hacia los EM, donde se producen el mayor número de irregularidades financieras en la práctica. Por ello, la Comisión persigue desde hace mucho tiempo que la gestión compartida se vea reflejada en una responsabilidad compartida. Sin éxito. Aunque se incluyó en el Tratado de Lisboa una coletilla en el nuevo artículo 317 TFUE: «Los EM cooperarán con la Comisión para garantizar que [emplean los fondos] de acuerdo con el principio de buena gestión financiera», obviamente los Estados Miembros en el seno del Consejo no están por la labor de atarse en este sentido.

Constituye ésta una grieta de responsabilización que obedece a una zona gris existente entre los niveles de gobernanza europeo y estatal (central, regional y local) con efectos perniciosos sobre la legitimidad de la UE como un todo pues los medios de comunicación están siempre prestos a exponer públicamente los casos de despilfarro comunitario.

${ }^{33}$ CIPRIANI, G., The EU budget, responsibility without accountability?, Bruselas, CEPS, 2010, pp. 66-70. 
Solamente los casos más graves de comportamientos desviados a nivel estatal son merecedores de sanción a nivel de la UE, cuando el TJUE enuncia un juicio negativo sobre los mecanismos de responsabilización nacionales. Baste recordar cómo España perdió el recurso contra la Comisión en el «caso del lino», entre críticas del TJUE a la existencia «de fraudes a gran escala», concluyendo que «la inactividad de las autoridades españolas ante las prácticas abusivas de los operadores españoles [...] constituye por sí sola un incumplimiento absoluto» ${ }^{34}$ de la normativa de la UE.

La falta de responsabilización del gestor nacional a nivel europeo no obstaría a la responsabilización sistémica si aquél rindiera cuentas ante el parlamento o tribunal de cuentas nacional por su gestión compartida del presupuesto UE, pero numerosos EM se han «centrado más en acapararlos [los fondos] que en vigilar y controlar su ejecución» y se han «despreocupado de los procedimientos que implican la devolución de las subvenciones europeas mal gestionadas» ${ }^{35}$, o bien es que los agentes nacionales de responsabilización «miran hacia otro lado» porque prima la solidaridad nacional sobre la solidaridad europea ${ }^{36}$.

¿Cómo abordan los agentes responsabilizadores de la UE esta grieta? Recurriendo al mecanismo blando de la exposición pública: por ejemplo, los informes del TCE nombran cada vez más a los EM incumplidores por su nombre, y la Comisión remite las observaciones al nivel estatal, presentando luego un informe conjunto con las reacciones de los EM, que en numerosas ocasiones se disfraza bajo la expresión «algunos Estados Miembros» ${ }^{37}$.

Queda por tanto un largo camino por recorrer hasta la responsabilización ordinaria individual de los EM ante instancias europeas en materia de gestión presupuestaria de fondos europeos.

Por las grietas de responsabilización expuestas puede fugarse, además, la legitimidad del proyecto de integración europea. Por ello cobra tanta importancia una comunicación institucional adecuada ante los ciudadanos, como se expondrá a continuación.

34 Asunto T-259/05 España contra Comisión, Sentencia del Tribunal de Primera Instancia de 1 de julio de 2009, Rec. II-00095, apdos. 181 y 183.

35 ORDÓÑEZ, D., «Las correcciones financieras por la gestión en España de los fondos europeos», Actualidad Administrativa La Ley, n. ${ }^{\circ} 4,2011$, p. 20, con respecto a España.

36 BACHTLER, J. y MÉNDEZ, C., «Administrative reform and unintended consequences: an assessment of the EU Cohesion policy "audit explosion"», Journal of European Public Policy, vol. 18, n. ${ }^{\circ}$ 5, 2011, pp. 746-765.

37 COMISIÓN, Respuestas de los EM al Informe Anual 2009 del TCE, COM (2011) 104, de 28 de febrero. 


\section{Comunicar Europa a los ciudadanos, recurso legitimador europeo de primer orden}

La comunicación es un eje prioritario para conseguir que los ciudadanos se identifiquen con el proyecto europeo. En una etapa de sincronías y asincronías producidas por la continua necesidad de tomar posiciones y situarse en un lugar en el puzzle global, la Unión Europea tiene ante sí misma un nuevo reto ambicioso y motivador: reconocerse en este entramado de modelos y de tendencias.

Para que Europa salga fortalecida en esta etapa de su proyecto siempre en marcha, esa es la propia esencia del proyecto europeo y su cualidad, virtud, es fundamental que los ciudadanos europeos miren a la UE con orgullo, identificándose con su democracia transnacional. Conseguir esta nueva meta, tiene que ir de la mano de una comunicación europea con vectores e iniciativas bien diseñadas y responsables. Es por esto, que la comunicación constituye en sí misma un elemento legitimador de primer orden. En este apartado expondremos ideas y modelos así como algunos ejemplos prácticos de cómo se teje la comunicación europea del siglo XXI desde las instituciones para motivar la creatividad de las organizaciones de la sociedad civil y de los propios ciudadanos que se convierten en ciudadanos «integradores».

\section{Un nuevo paradigma democrático: comunicación europea con visión de ida y vuelta}

Participación y comunicación son dos de los grandes retos europeos y comunicar para participar constituye un modelo de acción comunicativa. La comunicación constituye un recurso legitimador europeo de primer orden.

La responsabilidad institucional, ejercida de manera tangible, aumenta la confianza del ciudadano en sus instituciones y directamente la calidad democrática así como la credibilidad en la política. En el contexto de la UE, esta secuencia de responsabilidad, calidad y credibilidad conllevan el fortalecimiento de pertenencia a la UE de los ciudadanos y el sentimiento de ser ciudadano europeo.

Durante la última década se ha producido un cambio tanto en el concepto como en la forma basado en dos pasos fundamentales: el salto de la información a la comunicación y el que se produce en el mismo proceso comunicativo al tomar como eje de acción principal una comunicación de ida y vuelta. Esta comunicación, de doble sentido, es el firme objetivo de las instituciones europeas que concentran sus esfuerzos en encontrar fórmulas e iniciativas para que el ciudadano al recibir la información perciba la vo- 
luntad de una comunicación real y quiera emprender ese camino de vuelta hacia las instituciones y hacia sus representantes, los eurodiputados.

En este proceso, la democracia representativa se complementa con un ejercicio participativo. Estos vectores democráticos se conjugan en la configuración de un modelo europeo de debate que abrirá la fórmula de una política de comunicación europea.

Un primer hito en el cambio de la comunicación institucional se produce en las estrategias para comunicar Europa a los ciudadanos que impulsan el PE y la Comisión después de los «noes» de Francia y Holanda al Proyecto de Constitución europea ${ }^{38}$. La cita democrática para elecciones europeas 2009 es un segundo hito en relación a contactar con los ciudadanos europeos. El gran salto entre la campaña institucional para elecciones europeas 2004 y la campaña institucional comunicativa para elecciones al PE 2009 «Tu eliges» supone un concepto renovado en la comunicación institucional europea. La capacidad de conectar con los ciudadanos constituye uno de los indicadores sólidos de la «sostenibilidad» institucional europea para dar credibilidad al proyecto europeo: comunicar para motivar la participación son las claves para incentivar el voto en las elecciones europeas 2009.

En estos años, la búsqueda de herramientas para conectar con los ciudadanos ha sido uno de los retos europeos más importantes. Asimismo, se buscan la innovación y la creatividad para «enganchar» a la ciudadanía.

Llegar a los ciudadanos con los temas que preocupan a la gente a través de las vías y soportes que los ciudadanos utilizan, se convierte en un desafío para las instituciones europeas. Porque Europa ha pasado de estar en nuestra realidad a ser nuestra realidad pero esto los ciudadanos no lo saben, todavía. El reto es reconquistar a la ciudadanía para conectarla con Europa. En este apartado también veremos como se complementa la democracia representativa con un ejercicio participativo, a través de iniciativas y proyectos de las organizaciones de la sociedad civil, y cómo, durante la campaña común paneuropea hacia las elecciones europeas 2009, un vector importante para transmitir a los ciudadanos es el poder real del PE y su acción práctica en nuestro día a día.

El plan informativo del PE 2009 quiso provocar que el ciudadano de a pie se posicionase y tomase partido. Porque al elegir una u otra opción política está decidiendo sobre su futuro.

En el análisis de cómo son unas elecciones europeas desde las esferas participativa y comunicativa es necesario contextualizar en qué etapa de

38 Proyecto de Tratado por el que se instituye una Constitución para Europa, de 29 de octubre de 2004, DO C310, de 16 de diciembre. 
acción comunicativa se pone en marcha la «maquinaria» hacia las elecciones, cuál es el modelo de comunicación de la UE en esa fecha y con qué espacios de conexión para motivar la participación cuenta cada país.

La comunicación con los ciudadanos en la UE y en la acción comunicativa europea se dirige al objetivo de promover una participación ciudadana real y «que practique Europa».

Antes de exponer las ideas sobre cuál es el estado de la cuestión de la participación ciudadana europea es importante hacer referencia a la ciudadanía como concepto político y como proceso. En su contenido principal la ciudadanía conlleva un privilegio y también un deber y, en cuanto a su forma, tiene posibilidades de ampliarse, desarrollarse, dotarse de más significado y de operatividad o también de necesitar un tiempo de «encaje» a los nuevos tiempos y retos europeos. El reto en relación a la ciudadanía europea consiste en hacerla operativa e impulsar un ejercicio ciudadano porque, en el ejercicio de la ciudadanía, el hecho de sentirse ciudadano e identificarse con esta cualidad conlleva una motivación de los ciudadanos para interesarse por su comunidad, trabajar ejerciendo su ciudadanía y fortalecer la democratización de los procesos.

La ciudadanía activa es un elemento clave para conseguir un proyecto europeo políticamente ambicioso y socialmente integrador. En este sentido, hay que tener muy en cuenta que los ciudadanos tienen un poder integrador fundamental en la construcción de una Europa ciudadana. Estamos en una etapa en la que Europa y el mundo necesitan afrontar nuevos retos ante los desafíos del siglo XXI. La expansión globalizadora reclama, tanto al concepto de ciudadanía como a su «adaptación a los tiempos», una nueva perspectiva más dinámica, dialogante y participativa. Esta aplicación ciudadana a la democracia participativa europea, siempre en un sentido de complementariedad a la democracia representativa, plantea la necesidad de reactivar el ejercicio de la ciudadanía europea así como su progresión.

Este proceso conlleva una legitimación democrática en la UE así como el fortalecimiento de la democratización de la UE.

\section{Participación en la UE, comunicación y nueva gobernanza}

La participación articula sociedad y buscando información también se está participando, es por esto que la calidad en la comunicación conlleva una mayor integración política europea vertebrada en la democracia transnacional de la UE.

Los progresos de la participación ciudadana europea mucho tienen que ver con el papel de las ONG como multiplicadoras de información. En el proceso de construcción europea, las organizaciones y movimientos de la 
sociedad civil aportan ideas fortaleciendo la democracia y articulando el debate político. Relacionado con estos aspectos y su difusión, la comunicación con el ciudadano es decisiva en la nueva formulación de un espacio eficaz para el diálogo europeo, una Unión de fuerzas, de sinergias europeas. Los objetivos se dirigen fundamentalmente a la comunicación real a través de una mayor información a la ciudadanía, la creación de espacios de encuentros y convergencias, y la promoción y desarrollo de acciones que impulsen la ciudadanía activa y una nueva gobernanza ${ }^{39}$.

Los grandes activos de Europa son los ciudadanos y los valores. Una institucionalización «legitimada» se sostiene sobre estos dos grandes activos conjugando sus acciones en un marco democrático en el que la cesión de soberanías y la soberanía compartida son elementos esenciales en el proceso, y en el proyecto, integrador.

Actualmente bastantes estudios se dirigen a analizar las dimensiones y las actuaciones participativas en un marco democrático y ciudadano ${ }^{40}$. La atención hay que llevarla a la gobernabilidad relacionada con el desarrollo humano y con la democracia, observando la democracia participativa y las cuestiones que se plantean en relación a sus formas, vías y complementariedad con la democracia representativa. En este nuevo paradigma hay que tener en cuenta dos ejes: el enfoque hacia un centralismo global y el potencial del liderazgo descentralizado local. La participación es un elemento clave en la renovación democrática de la UE, una Europa participativa es la vía para involucrar a la ciudadanía en el proyecto y promover un sentimiento europeo común.

Es desde el debate con la sociedad civil, desde donde se puede llevar a cabo un cambio en la percepción que los ciudadanos tienen de Europa y el establecimiento de un nuevo paradigma en el proceso de creación política.

\section{Un hito participativo para un modelo constituyente: la Convención europea}

Es durante la Convención, encargada de escribir la Constitución, cuando la participación de los movimientos y organizaciones de la sociedad

39 Sobre gobernanza, vid. en documento con el programa de la Presidencia danesa del Consejo de la UE (primer semestre de 2012) dentro del trío de Presidencias (Polonia, Dinamarca y Chipre). La gobernanza aplicada al medio ambiente en relación a la estrategia sostenible (p. 60), Europe 2020 (p. 69) y la referencia importante al programa «Europe for Citizens» de la Comisión en la página 74: http://register.consilium.europa.eu/pdf/en/11/st11/ st11447.en11.pdf, http://eu2012.dk/en/EU-and-the-Presidency

40 Vid. DASTOLI, P.V., «The Role of Organised Civil Society in European Governance», en COMITÉ ECONÓMICO Y SOCIAL, Organised Civil Society, Participatory Democracy and the Reform of Modes of Governance, 2001, Bruselas. 
civil tiene una mayor visibilidad, repercusión y escucha. Con la Convención europea, la participación consigue otra dimensión.

El modelo Convención hizo posible la participación de la sociedad civil de una manera institucionalizada y con una escucha sin precedentes en el proceso de reforma de los Tratados. A la Convención no se le pide un listado de reformas puntuales sino una propuesta de futuro para la construcción europea, sus finalidades, sus instrumentos y sus métodos: un proyecto de simplificación de los Tratados y de reforma de las instituciones que pudiese convertirse, si esa era la voluntad mayoritaria, en un proyecto de Constitución. La búsqueda del consenso a través del debate fue el motor en la elaboración de una Constitución para Europa ${ }^{41}$.

Durante 50 años sólo los gobiernos habían negociado y preparado en exclusiva los Tratados, es con la preparación de una Constitución para Europa cuando se abre un proceso en el que se da un papel emergente a la participación de los parlamentos y a un diálogo estructurado y permanente. En este diálogo se implicaba a la sociedad civil junto con las instituciones europeas, estatales y regionales. El proceso quedó explícitamente formulado como hoja de ruta en los trabajos de la Convención y continúa siendo un modelo ejemplar de interconexión. Al protagonismo de los Estados miembros, se le añade el papel relevante de los órganos legislativos así como el reconocimiento explícito de la necesidad del debate público y de la participación de la sociedad civil.

A través de un Foro, interfaz entre los miembros de la Convención y las organizaciones de la sociedad civil, se consiguió una comunicación de ida y vuelta a la que antes se ha hecho referencia. La Declaración de Laeken de diciembre de $2001^{42}$, reconoce institucionalmente el foro y otorga a la sociedad civil un papel determinante en el proyecto europeo siendo, al mismo tiempo, actora y «elemento-poder» constituyente en si misma. El Foro significó la puesta en práctica del diálogo a dos niveles: en horizontal, entre las Organizaciones No Gubernamentales y movimientos, y en vertical, con la propia Convención. Este Foro fue un lugar de encuentro y de intercambio de ideas con una dinámica que mostraba la eficacia de un método de futuro. Funcionaba. La participación formal y práctica de la sociedad civil y la invención de un modelo tuvieron su lugar en la Convención. De esta manera, la participación

${ }^{41}$ DEL RÍO VILLAR, S., Comunicar, clave para aumentarla la participación en las elecciones europeas de 2009: de un modelo europeo de debate a una política comunicativa europea, primera parte, ARI 88/2009, Real Instituto Elcano: http://www.realinstitutoelcano.org/ wps/portal/rielcano/contenido?WCM_GLOBAL_CONTEXT=/elcano/elcano_es/especiales/ eleccionesparlamentoeuropeo/analisis-publicaciones/publicaciones+rie/ari88-2009

42 Declaración de Laeken sobre el Futuro de Europa y Foro de la Convención europea: http://european-convention.eu.int/forum.asp?lang=ES 
de la sociedad civil y su formalización, como actora en la apertura del proceso constitucional, permitía su inclusión en el método de toma de decisión en un marco político de primera magnitud. Gracias al método, se producía un salto cuantitativo y cualitativo en la democratización de la Unión.

Desde la etapa de la Convención la constitucionalización de la UE es una realidad más tangible por los ciudadanos. En este sentido, otra sinergia adquiere un mayor protagonismo: la social, ya que un proceso constitucional abierto implicaba que el actor social se encuentra enraizado al mismo y a su poder constituyente. Incluso con el impasse que se produjo después de los «noes» de Francia y de Holanda a la Constitución Europea, el Tratado de Lisboa contiene la esencia constitucional y el recorrido ha servido para implicar a los ciudadanos en la $\mathrm{UE}^{43}$.

Si nos concentramos en las contribuciones expuestas desde la sociedad, observamos que lograron hacerse visibles los temas que expresan el modelo social y la solidaridad en el centro del proyecto europeo. Sus propuestas se dirigieron fundamentalmente a aquellos puntos enlazados con la vida democrática de la Unión: los valores, la subsidiariedad basada en la horizontalidad, un sistema transparente, la democracia participativa, la Iniciativa Legislativa Ciudadana (en la actualidad Iniciativa Ciudadana Europea, art. 11.4 TUE), el diálogo civil y el reconocimiento de las asociaciones de la sociedad civil.

En los comienzos de los trabajos de la Convención, la contribución del Foro Permanente de la Sociedad Civil «La arquitectura de la Constitución Europea», exponía la idea de «un desplazamiento del paradigma», explicando que el lanzamiento de la Convención, para la revisión del Tratado, era uno de los signos del desplazamiento del sistema en los procesos de toma de decisiones ${ }^{44}$.

Las Organizaciones No Gubernamentales y movimientos de la sociedad civil continúan insistiendo en que el modelo de la Convención ha ayudado a progresar hacia una Unión que sitúe a los ciudadanos en la base de su proyecto y a vencer el abismo existente entre instituciones y ciudadanos. Los puntos fundamentales se centraron en: democratización y reforma constitucional; cometido y competencias de la Unión y de los países miembros e identidad, sensibilidad y «espacio público en Europa». El documento también resaltaba la importancia del flujo de ideas e información a través de Europa. Las organizaciones destacaron que el «método-convención» debía convertirse en el nuevo jalón que prepare el ca-

${ }^{43}$ Sobre los hitos del proceso: http://ec.europa.eu/archives/institutional_reform/

${ }^{44}$ Las principales contribuciones del Foro Permanente de la Sociedad Civil durante los trabajos de la Convención pueden encontrarse en: http://en.forum-civil-society.org/spip. php?article60 
mino hacia una Europa realmente de los ciudadanos. Durante la etapa de reflexión abierta tras la Constitución europea, las redes de la sociedad civil continuaron afirmando la necesidad de dar al modelo de trabajo de la Convención una continuidad. Un ejemplo es el Grupo Spinelli que ha lanzado la llamada a una nueva Convención junto con propuestas de corte federalista y aportaciones sobre elecciones con listas paneuropeas hacia las elecciones 2014 al $\mathrm{PE}^{45}$.

De esta manera, la superación del método intergubernamental tuvo en las iniciativas del PE y en la propia sociedad civil sus principales impulsores. Todo esto representó un cambio considerable. A pesar de la etapa de impasse después de la negativa de Francia y de Países Bajos al Proyecto de Constitución Europea, la dinámica de trabajo y la formulación de espacios para la comunicación y el debate adquirieron fuerza y consolidación. Esta acción comunicativa ha tenido una continuidad tanto en las estrategias de comunicación emprendidas por las instituciones europeas como en el lanzamiento de nuevas iniciativas impulsadas desde las organizaciones de la sociedad civil también durante el emocionante trayecto hacia la ratificación del Tratado de Lisboa.

\section{Creatividad comunicativa para proyectos impulsores de ciudadanía europea}

Desde hace tiempo se han lanzado iniciativas comunicativas para conectar con los ciudadanos pero tras el «parón» a la Constitución europea emerge la necesidad apremiante de dar a conocer Europa a la sociedad y hacerla partícipe de lo que está sucediendo en la UE.

Una Europa participativa promueve unos esquemas específicos y la exploración de nuevos mecanismos que constituyan los anclajes hacia unos espacios concretos y conocidos por los ciudadanos ${ }^{46}$. A continuación se revisarán las iniciativas de mayor repercusión puestas en marcha desde las instituciones con la intención clara de conectar con los ciudadanos para motivar la participación.

La renovación del sitio web del $\mathrm{PE}^{47}$ mostró que la información no debe ser restringida sino abierta. Una información que desarrolle un modelo

45 http://www.spinelligroup.eu/2011/01/13/spinelli-debate/

46 DEL RÍO VILlAR, S., Ciudadanía activa en Europa. Proceso participativo y nuevos espacios para la comunicación, Difusión jurídica y temas de actualidad, Madrid, 2008.

47 PARLAMENTO EUROPEO, http://www.europarl.europa.eu/news/public/default_ es.htm; web de su Oficina en España: www.europarl.es y sitio web dedicado a las elecciones 2009: www.europarl.europa.eu/elections2009/default.htm?language=es 
de funciones transversal y que una comunicación variada, multidireccional e integradora, que cuenta con una puesta en pantalla impactante, no supone que las instituciones europeas deban abandonar su papel clave, tanto como comunicadores activos como diseminadores de información. La web, también dirige sus esfuerzos a dar más información, de una manera más sistemática, a los periodistas. Este aprendizaje «mediático» de lo europeo, conllevará una mayor asimilación de Europa por la ciudadanía.

Hay que resaltar la iniciativa Ágora organizada por el Parlamento Europeo e impulsada fundamentalmente desde su comisión de Asuntos Constitucionales para integrar a los ciudadanos en el debate europeo. En la primera Ágora del PE, celebrada en noviembre de 2007, participaron más de cuatrocientos representantes de organizaciones de la sociedad civil. El hilo conductor: «El futuro de Europa: retos, oportunidades e instrumentos derivados de los nuevos tratados». Los grupos de trabajo se estructuraron en relación a estas acciones: Tareas, Herramientas, Fronteras y Horizontes. En junio de 2008 se celebraba el segundo Ágora del PE dedicado a un tema tan prioritario y de actualidad como es el cambio climático: Climat Change: analysing, problem solving, mobilizing. Los grupos de trabajo centraron sus debates en los siguientes temas: recursos, técnicas, solidaridad, economía y educación.

El punto fuerte del Ágora del PE es que lo lanza la institución europea que representa directamente a los ciudadanos, involucrando a representantes de organizaciones de la sociedad civil que pueden aportar ideas importantes para la nueva etapa de la UE. Ágora es un instrumento nuevo que conlleva una logística enorme en un marco, el PE, donde se hace visible una complicidad eurodiputados-ciudadanos.

El «Plan D» (democracia, diálogo y debate) lanzado por la Comisión ${ }^{48}$, colocaba en el centro del proyecto la democracia, el diálogo y el debate para comunicar con los ciudadanos. Los temas fundamentales de esta propuesta giran en torno a tres ejes: estimular un debate público en profundidad, promover la participación de los ciudadanos en el proceso democrático y poner al alcance, tanto de las instituciones como de las organizaciones, las herramientas necesarias para generar el diálogo sobre las políticas europeas y el método de toma de decisión. En la actualidad en el programa Europa a debate, construir a partir de la experiencia del Plan D: Democracia, Diálogo y Debate, la Comisión quiere dar continuidad al debate con la participación de los ciudadanos promoviendo su contacto permanente con las ideas y los valores intrínsecos al proyecto europeo.

Como antes hemos apuntado, las iniciativas del Parlamento incluyen la renovación de su web y el lanzamiento de Europarl TV y la web dedi-

${ }^{48} \mathrm{http} / /$ ec.europa.eu/commission_barroso/wallstrom/pdf/com_2008_158-4_en.pdf 
cada a las elecciones europeas. Desde la Comisión Europea continúan en el periodo 2007-2013 las iniciativas Europa con los ciudadanos y Europa a debate. La Representación en España, en su voluntad por crear un espacio público europeo de reflexión y debate para llegar a públicos a los que normalmente no interesa la información comunitaria, pone en marcha una nueva web participativa, espacio Europa ${ }^{49}$, para promover un espacio público europeo. También en el campo audiovisual, el programa Europa 2011, Europa 2012, de TVE, íntegramente dedicado a los temas europeos, busca cada semana acercarnos a las noticias de actualidad de la UE a través de reportajes de temática variada, análisis y entrevistas utilizando un formato ágil y cercano. Desde Secretaría de Estado para la UE en España, el espacio web Hablamos de Europa ${ }^{50}$ va mostrando información actualizada día a día sobre asuntos europeos, debates, seminarios y noticias de interés transmitidas de manera fácil y directa.

Las Consultas Europeas a la Ciudadanía. Haz oír tu voz es una iniciativa paneuropea formulada en el marco de proyectos de la Comisión Europea, impulsada por la Fundación King Baldouin (Bélgica) y en España desarrollada por la Fundación Luís Vives. El punto fuerte de este proyecto, en el que los protagonistas son Europa y sus ciudadanos, es el debate paneuropeo, la escala transnacional y poder mostrar a los ciudadanos que sus propuestas importan. El elemento destacable: la capacidad de los ciudadanos para dialogar, debatir y llegar a un consenso sobre los puntos a incluir en las conclusiones finales. En las European Citizens Consultations 20062007 los temas que identificaron los ciudadanos como prioritarios fueron: inmigración, política social y familiar y medio ambiente. La ECC2009 hace una sola pregunta a los ciudadanos: « ¿Cómo puede la UE afrontar nuestro futuro económico y social en un mundo globalizado?». De los debates con los ciudadanos salieron diez recomendaciones desde cada país. Además, un grupo de observadores participó en la Consulta europea en España siguiendo de cerca la metodología, escuchando a los cien ciudadanos y debatiendo sobre la misma pregunta. En la consulta paneuropea, celebrada en mayo de 2009, se pusieron sobre la mesa las propuestas de cada país acordándose las quince recomendaciones comunes de los 27 países, la recomendación más votada fue la lucha contra el cambio climático.

En el contexto hacia las elecciones al Parlamento Europeo 2009, después del acuerdo entre el Parlamento Europeo y la Comisión Europea para «comunicar Europa en partenariado», las instituciones europeas lanzaban la

49 Espacio Europa: http://espacioeuropa.eu/; página en la web de la Representación de la Comisión Europea en España http://ec.europa.eu/spain/index_es.htm

${ }^{50}$ Hablamos de Europa (Secretaría de Estado para la UE): www.hablamosdeeuropa.es/ Paginas/Home.aspx 
campaña con el mensaje: «Tú eliges», uniendo sus fuerzas para incentivar la participación. En esta línea de conexión con los ciudadanos, el PE aprobaba el 12 de enero de 2009 por gran mayoría el informe de la comisión de Asuntos Constitucionales sobre las perspectivas para el desarrollo del diálogo civil en el marco del Tratado de Lisboa ${ }^{51}$.

La campaña de comunicación del PE para las elecciones europeas $2009^{52}$ buscó incentivar la participación comunicando, con herramientas innovadoras, temas de actualidad que preocupan a los ciudadanos, que hacen pensar en las opciones impulsando una opinión pública europea. El plan informativo, común a los 27 países, tuvo una visión transnacional y de vanguardia comunicativa. Una campaña transversal provocadora y común, porque la sensación desde el Parlamento Europeo es que hay un espacio ciudadano europeo que ya se puede enganchar a la misma Europa.

El PE estuvo activo en plataformas como facebook y twitter junto con recursos más tradicionales como son los pósters y anuncios y continúa después de las elecciones utilizando esta herramienta de comunicación, las redes sociales. Retomando el plan informativo, incluso los pósters de la campaña tuvieron elementos innovadores ya que con unos diseños claros de dibujos en relación a temas de actualidad en la UE se quería provocar que el ciudadano de a pie se posicionase y tomase partido. Porque el mensaje fue que, al elegir una u otra opción política en unas elecciones europeas decidía directamente sobre su futuro en los próximos cinco años ${ }^{53}$.

También hay que destacar el anuncio oficial de televisión y varios vídeos grabados para difusión por internet. En el anuncio nos «transportamos» a un futuro en el que, dependiendo de lo que elijamos, escucharemos más adelante una noticia u otra diferente respecto a temas de actualidad. Esta «conjugación» de tiempos, nos lleva a pensar en una Europa con futuro y en una UE en el futuro. La campaña mostró un recorrido temporal claro para que los ciudadanos sepan que lo que eligen en las elecciones europeas tiene una consecuencia, que importa nuestra decisión.

${ }^{51}$ PARLAMENTO EUROPEO, Informe Grabowska de la Comisión de Asuntos Constitucionales sobre las perspectivas de desarrollo del diálogo civil en el marco del Tratado de Lisboa de 4 de diciembre de 2008, A6-0475/2008.

52 Elecciones europeas, página web del Parlamento Europeo en la que encontramos también los resultados de las elecciones desde el día 7 de junio: www.europarl.europa.eu/ elections2009/default.htm?language $=$ es

53 Para una visión más completa véase: DEL RÍO VILLAR, S., Comunicar, clave para aumentar la participación en las elecciones europeas de 2009: nuevos espacios, proyectos ciudadanos y plan de acción informativa del Parlamento Europeo, Análisis, segunda parte: ARI 90, para el Real Instituto Elcano, junio de 2009. http://www.realinstitutoelcano.org/wps/ portal/rielcano/contenido?WCM_GLOBAL_CONTEXT=/elcano/elcano_es/zonas_es/ari902009 
Siguiendo con la comunicación y la presencia activa del PE en las redes sociales, en otoño de 2010 comenzó la puesta en marcha de dos nuevos proyectos. «Citzalia» ${ }^{54}$, impulsado desde la ESN (European Service Network), sin duda es diferente y sorprende. El objetivo es llegar a otros ciudadanos quizás más jóvenes o con mayor «enganche» a juegos multimedia y a lo «virtual» y con ganas de tener un avatar que entre y salga del PE, proponga y hasta «haga política». Sin duda es una apuesta diferente, habrá que esperar a ver su funcionamiento y capacidad para motivar la participación.

Otro proyecto innovador es «Tweet your MEP» ${ }^{55}$, iniciativa de Toute l'Europe que será sin duda un activador para la conexión de los eurodiputados con los ciudadanos, de la política con «la calle», con el ciudadano de a pie.

Las instituciones europeas continúan renovando sus proyectos de comunicación con algunas novedades. La Comisión Europea pone en marcha un plan de comunicación más personalizado, y centralizado en su Presidente José Manuel Barroso, con líneas de actuación definidas, y muy convergentes, en relación a prensa, espacios y revolución comunicativa digital ${ }^{56}$. La conexión con los ciudadanos y las nuevas iniciativas emprendidas por la Comisión se encuentran explicadas en la página de la vicepresidenta Viviane Reding, comisaria de Justicia, Derechos Fundamentales y Ciudadanía ${ }^{57}$.

Respecto al papel de los blog europeos, desde su estética, presentación y personalidad contribuyen a motivar debate y a generar opinión pública europea.

\section{Activadores de proyecto europeo: fortalecer la integración de la UE}

Se hace necesaria una política de información clara y bien implementada que permita que la ciudadanía conozca de manera eficaz y completa qué es lo que se está decidiendo en las instituciones europeas, cuáles son las posiciones de los Estados miembros ante los temas de actualidad y cuál es la perspectiva que cada partido político europeo tiene sobre un asunto determinado.

Para conseguir una comunicación integral es fundamental crear un elemento con personalidad europea, un branding europeo. El concepto branding es un anglicismo que se aplica a la creación de una marca y que mucho

\footnotetext{
${ }^{54}$ http://blog.citzalia.eu/

55 http://www.tweetyourmep.eu/

$56 \mathrm{http}: / /$ ec.europa.eu/dgs/information_society/see_more/vb/index_en.htm

57 http://ec.europa.eu/commission_2010-2014/reding/
} 
tiene que ver con la capacidad comunicativa de llegar a la gente y a conseguirlo. La sinergia del brandan también nos interesa aplicada a la comunicación europea y a sus mecanismos y engranajes del modelo europeo, de la «marca» europea, porque lleva implícita una forma de entender la comunicación de manera integral ${ }^{58}$.

¿Cómo transmitir qué es la UE a la ciudadanía con una información comprensible, eficaz, contrastada y frecuente? Se ha producido una continua redefinición de espacios que los medios de comunicación deberían aprender a abordar. Los medios tienen que moverse de manera sincronizada para poder añadir algo más a su capacidad comunicativa: conseguir que los ciudadanos perciban una idea europea coherente y común, ¿cómo conseguirlo?: transmitiendo en «versión europea», buscando un código común europeo «que llegue».

Es fundamental un seguimiento europeo desde las instituciones y entidades de la cadena informativa instituciones-medios-ciudadanía, ya que los medios de comunicación tienen un papel determinante en conducir la opinión pública ${ }^{59}$. Los medios de comunicación tienen un papel como agentes de socialización. Es este aspecto en el que los medios pueden ser conductores de informaciones transnacionales y constructores de comunicación paneuropea. Un actor que hay que tener muy en cuenta son las asociaciones y ONG como multiplicadoras de información hacia el ciudadano. La capacidad solidaria de la UE es fundamental a la hora de comunicar Europa y crear interés por Europa ya que los ciudadanos se sienten identificados con los movimientos sociales y con las causas solidarias, humanitarias. La solidaridad es un gran activador de ciudadanía.

También la juventud ocupa un lugar prioritario entre los actores impulsores del desarrollo europeo. La educación tiene que establecerse como ámbito de mucha atención en toda estrategia comunicativa: los jóvenes son el futuro de Europa. En la vida cotidiana, otro catalizador importante es la cultura.

La tecnología de la información y la comunicación articulan y tienden el entramado de las relaciones en red para la organización de los movimientos promoviendo la acción colectiva y el debate, mediante la politización, y la socialización, en la vida cotidiana. Esta actividad en red también

58 Resalto el concepto branding en relación a la «marca» europea en un sentido de identificación de los ciudadanos con Europea y de llegar al ciudadano de a pie. Un ejemplo para conseguir de manera continua esa identificación visual y emotiva hacia la UE son las Presidencias en Trío que buscan unos logos con continuidad así como algunos ejes comunes.

59 Vid. DUCH, J., «Unión Europea, opinión pública y política de información», en DEL RÍO VILLAR, S. (coor.), Europa: el estado de la Unión, Aranzadi, Cizur Menor, 2006, pp. 57-77. 
funciona cultivando y estimulando la participación popular. A su vez, los programas participativos constituyen, fundamentalmente, procesos de comunicación con una enorme energía potencial. No hay que pensar en términos instituciones, gobiernos, ciudadanos, nosotros y ellos, sino en una labor conjunta y en la creación de una responsabilidad común y de un conocimiento cívico de Europa.

Como antes hemos expuesto, el PE impulsó su propia revolución en las elecciones europeas 2009 estando presente en las redes sociales. Otro asunto es el de la participación y hay que resaltar que la campaña común paneuropea fue en muchas ocasiones eclipsada por la política nacional. Resaltar que el plan de información dio un salto de gigante respecto a las elecciones al PE 2004 reforzando la consolidación de una política de comunicación europea.

\section{Esferas, conexión y comunicación: reflexiones sobre democracia europea y ciudadanos «integradores»}

La UE está definiendo la acción conjunta con los ciudadanos. Si de algo sirvió la etapa de reflexión que siguió a la interrupción del proceso de ratificación de la Constitución europea fue para que las instituciones comunitarias se diesen cuenta que tenían que «recuperar a los ciudadanos», primero informándoles de manera más próxima y accesible y, segundo, estableciendo unos espacios para la comunicación y un código común de intercambio de ideas.

Acerca del Tratado de Lisboa, es importante transmitir una idea a los ciudadanos: que el Tratado es un elemento habilitador para continuar avanzando, su esencia es constitucional y aporta herramientas para reactivar la capacidad de los ciudadanos de ejercer su ciudadanía y de participar en los asuntos que les importan como son energía, seguridad, cambio climático, educación etc.

La democracia europea contiene múltiples dimensiones de actuación y de ejercicio democrático multinivel en el que se inserta el debate sobre el demos europeo ${ }^{60}$. En la Europa del siglo XXI, un objetivo de la Unión es que los ciudadanos «sintonicen Europa», comiencen a ver Europa en su día a día y descubran el potencial de la UE: Europa como oportunidad. Se trata de sincronizar procesos con continuidad, y formulados de manera sostenible, para reconquistar el espacio ciudadano.

60 WEILER, J.H.H., HALTERN, U. y MAYER, F., «European Democracy and Its Critique. Five Uneasy Pieces», Jean Monnet Working Papers 1/95 http://centers.law.nyu.edu/ jeanmonnet/papers/95/9501ind.html 
Un reto importante es encajar las piezas de actuación y de coordinación entre el PE, los parlamentos nacionales y los parlamentos regionales. Esta esfera de comunicación interparlamentaria sin duda constituye un ámbito clave para acercar Europa a los ciudadanos y también para configurar nuevos círculos concéntricos de actuación y de interactividad europea. En esta línea de acción se encuentra la resolución aprobada por el Parlamento sobre las relaciones entre el PE y los parlamentos nacionales en el marco del Tratado de Lisboa. En la actualidad se da lo que se denomina el diálogo político informal y el reto será reforzar el diálogo pre y post legislativo entre el PE y los parlamentos nacionales.

También las Organizaciones No Gubernamentales han expuesto sus posiciones a las instituciones europeas en relación a su implicación en el método de toma de decisión y a sus propuestas hacia una Europa más social en esta etapa de crisis económica. Al respecto, la organización Solidar: European Social Policy ha elaborado un documento recientemente: «10 priorities for 2009-2014. Deliverables for the new European Parliament and new European Commission ${ }^{61}$.

La configuración comunicativa europea muestra un poder integrador clave en el futuro de la UE así como un nuevo trayecto movilizador involucrando a la ciudadanía. Para dotar de pragmatismo a Europa, también las organizaciones aportan ideas democratizando el proyecto y articulando una estructura para el intercambio de opiniones que ayude a consolidar una arena pública común.

Nos hemos acercado a las nuevas oportunidades que desde las instituciones europeas, en sincronía con los movimientos de la sociedad civil, están permitiendo renovar los mecanismos europeos de participación existentes. Si la Convención europea hizo posible la visibilidad de un modelo europeo de debate con un motor: la búsqueda del consenso, este modelo de debate ya tiene un espacio comunicativo europeo en donde desarrollarse.

Respecto a las nuevas tecnologías y el recurso Internet es importante que la gente se enganche al dominio eu. Es decir, conseguir un modelo de comunicación política europea y transmitir con un código comunicativo ciudadano. El movimiento es: comunicar para motivar la participación y la secuencia es: comunicación, ciudadanía, conexión y...una p de participación.

La sincronía de los vectores que conjugan sus fuerzas en este nuevo espacio emergente de comunicación política, institucional, asociativa y ciudadana tiene valor tanto en sí misma, en su propio juego, como en los objetivos alcanzados. En el proceso de integración europea este es un paso más

61 SOLIDAR, 10 priorities for 2009-2014. Deliverables for the new European Parliament and new European Commission, Briefing paper n. ${ }^{\circ}$ 10, 2009, http://cms.horus.be/ files/99931/MediaArchive/SOLIDAR\%2010\%20Deliverables\%2012062009_mail.pdf 
de gran avance: una política de comunicación europea, una Europa comunicada....con sus ciudadanos. La comunicación es un reto que cambiará Europa. En el ejercicio democrático de vanguardia, las organizaciones de la sociedad civil consiguen un avance en el concepto de ciudadanía europea hacia una nueva ciudadanía identificada con Europa.

Muy recientemente, se ponen en marcha estrategias y sinergias comunicativas junto con la formulación de metodologías para su desarrollo. Se quieren consolidar modelos y dar el salto desde los «planes «piloto» a la implementación con continuidad. En este sentido, volver a destacar el cambio en el paradigma de comunicación institucional europea al hacerse visible un salto conceptual y de transmisión del mensaje desde la campaña institucional para las elecciones al PE 2004 al plan de acción comunicativa del PE para las elecciones 2009.

Volviendo a subrayar que la capacidad de conectar con los ciudadanos constituye uno de los indicadores sólidos de la «sostenibilidad» institucional europea para dar credibilidad al proyecto europeo, resaltar que comunicar para motivar la participación son las claves para incentivar el voto en las elecciones al PE 2009 y en la actualidad hacia las elecciones al PE 2014.

En esta apasionante tarea comunicativa hay varias sinergias esenciales para comunicar «en versión europea» y continuar configurando un espacio europeo común de debate: sincronizar y explorar espacios para la comunicación, impulsar una ciudadanía activa, mostrar una Europa tangible, práctica, de calle y transmitir Europa de forma accesible, ágil y con un lenguaje sencillo. Desplegar el potencial del recurso Comunicación, solidario, creativo e innovador, conlleva una acción comunicativa con los ciudadanos y desde ellos. Se trata de sincronizar procesos sostenibles de participación ciudadana que permitan reconquistar el espacio ciudadano para conectarlo con Europa.

Como conclusión, resaltar el eje vertebrador expuesto al comienzo de este apartado: el poder de la vertiente comunicativa para aumentar la legitimidad de la UE. Y, siguiendo esta idea, volver a afirmar que la responsabilidad institucional, aumenta la confianza del ciudadano en sus instituciones y hace visible calidad democrática otorgando a la política credibilidad a los ojos de los ciudadanos. En la Unión Europea de nuestros días, y aún más en una etapa de convulsión multinivel, esta secuencia de responsabilidad, calidad y credibilidad es fundamental para fortalecer el sentimiento de pertenencia a la UE de los ciudadanos.

\section{Conclusión}

La gobernanza democrática en la Unión Europea funciona en un sistema multinivel que, por su idiosincrasia, plantea retos constantes de legi- 
timación del proyecto de integración europea. A lo largo de este artículo, hemos expuesto la importancia de buscar permanentemente soluciones progresistas que mejoren sin cesar dos vectores de legitimación democrática: la responsabilización institucional y la comunicación.

En el proceso de integración europea, la UE ha evolucionado hacia un sistema de responsabilidad difuso integrado por sujetos y mecanismos de distinta naturaleza y eficacia que conjuntamente y constantemente presionan sobre el sistema para optimizar sus posibilidades y legitimarlo ante los ciudadanos. Para su mejor comprensión, se ha propuesto un acercamiento a los distintos mecanismos responsabilizadores, en cuanto a su naturaleza, los sujetos que participan y su potencial eficacia. La mera existencia de un contexto general de cultura de la responsabilidad tiene un efecto legitimador, pero es necesario que el ejercicio de exigencia y rendición de cuentas sea eficaz para que tal efecto no se desvanezca. Por esto, no hay que bajar la guardia ante las posibles grietas de responsabilización que existen y las que surjan. En este estudio hemos ilustrado mediante sendos ejemplos las fugas de responsabilización producidas cuando el agente no ejerce su función responsabilizadora con el celo debido o bien cuando, en la gestión multinivel de políticas públicas, el ejercicio de poder no va acompañado de una responsabilización equivalente. Debe distribuirse equitativamente las cargas de la responsabilidad, atribuyendo honestamente al nivel estatal las fugas de responsabilización cuando corresponda.

Además, las instituciones de la UE han tomado conciencia de que la comunicación institucional es un eje de legitimación fundamental y exploran de modo creativo y cada vez más fluido nuevas dimensiones para consolidar una relación con los ciudadanos que les acerque y les convierta en vector de integración europea. La habilidad para promover una comunicación paneuropea que apunte a los temas y enfoques europeos permite sellar algunas fisuras multifacéticas que existen entre los ciudadanos y las instituciones para conseguir que se involucren y adhieran al proyecto de integración europea con el resultado de una mayor legitimación democrática de éste. 